\title{
Bystanders are the Key to Stopping Bullying
}

\author{
Ms. Sharon Padgett, Dr. Charles E. Notar \\ Jacksonville State University \\ *Corresponding Author: cnotar@jsu.edu
}

Copyright (C) 2013 Horizon Research Publishing All rights reserved.

\begin{abstract}
Bullying is the dominance over another. Bullying occurs when there is an audience. Peer bystanders provide an audience $85 \%$ of instances of bullying. If you remove the audience bullying should stop. The article is a review of literature (2002-2013) on the role of bystanders; importance of bystanders; why bystanders behave as they do; resources to help bystanders, parents, and schools to combat bullying; and established anti bullying programs with a bystander component are discussed.
\end{abstract}

Keywords Bullying, Bystanders, Cyberbullying, Special Needs

\section{Introduction}

Today, bullying is widely regarded as a serious problem in the United States. On an average school day, three out of ten American school children in grades six through ten are involved in bullying - as perpetrators, victims, or both according to the National Institute of Child Health and Human Development [1] [2]. Bullying has been accepted as a "rite of passage" which built "character." Today, however, it is no longer regarded as a "rite of passage"; rather it is just something that happens during playground experiences. Unfortunately, teasing is and always has been a part of growing up - almost everyone experiences it. However, teasing becomes bullying when it is repetitive or when there is a conscious intent to hurt another.

Bullying is a strategy to gain control or power at the expense of others. Name-calling, threats, physical attacks and property damage, or peer pressure can all be forms of bullying. Pellegrini [3] also found the issue of bullying features prominently in educational administration, academic research, journalism, and public discourse. Bullying is an issue that is prevalent in all schools at all age levels. Bullying is a major form of school violence that threatens a child's development and learning. Bullying involves antisocial behavior exhibited in high levels of aggression, bullying of others, defiance of adults; and in more mature youths, vandalism, stealing, and self-abuse expressed through involvement with drugs and alcohol. Policy and research in education and educational psychology has only minimally spoken to the social dynamics of school organization or peer groups that may underlie this crisis. Research shows that bullying entails a combination of school- and peer-level factors contributing to bullying, victimization, and sexual harassment.

We must understand adolescents face pressures to live up to the norms of their friendship group [4] [5] which may include involvement in bullying behaviors. For this reason, the friendship network and the pattern of friendships among individuals within a group is an important aspect of adolescent school bullying as stated by [6] [7] [8] [9] [10] [11].

The research establishes four groups that are involved in bullying. Most of the research list bullies, victims, bully-victims and bystanders as the characters playing roles in bullying. The authors' definition of bullying is defined as purposefully aggressive behavior that is used repeatedly, with the intent to cause some form of harm, and generally committed by a person who holds a form of power over the victim in a permissive environment. The authors defined a victim of bullying as a student exhibiting negative attitudes and beliefs about themselves and others, low social competence, inadequate social problem-solving skills, poor academic achievement, and not only rejected and isolated by peers but also negatively influenced by the peers with whom he or she interacts. A bully-victim is one who engages in aggressive behaviors and is also a victim of aggression. [12] [13].

In this article the fourth character in bullying, the bystander, will be examined. Bystanders are individuals who are neither victims nor perpetrators of bullying. Bystanders are extremely important actors in deterring the demoralizing and damaging impacts of bullying. Heinrichs [14] found bystanders to represent the largest group in numbers of the four characters. Bullying almost always occurs in front of other students. The bystander usually accepts or even participates in the bullying or they may try to stop the bully and take up for the target. Another definition of the bystander is someone who is uninvolved nonbully/nonvictims peer onlookers who treat victims of bullying based on their status within the population. These individuals are facilitators of the bully [15]. In this article the authors use the terms peer and bystander interchangeably. 


\section{Importance of Bystanders}

Bullies like an audience, and bullying is often a public interaction in which there are perceived winners and losers. While some victims are targeted because of a perceived vulnerability or difference, it is also accurate that anyone can become a victim of bullying. As such, students intuitively weigh their own chances of becoming victims and maneuver to avoid it. They find relative safety in the bystander position. A recent study by Jeffrey [16] found peers present in $85 \%$ of bullying episodes, but intervened in only $10 \%$. Therefore, mobilizing bystander reaction is an important approach to preventing bullying. Suggestions for preventing bullying are discussed at the end of this article.

Youths classified as bullies were more likely to attribute the reason for bullying to the victim and much less to the bully, compared to victims, bystanders, and victims/bullies [17]. All of the research evidence suggests that, at least in middle school, bullying may be a group process in which many children - and educators - have a part as indicated by Espelage, Green, and Wasserman [18]. She pointed to studies showing that in $85 \%$ of schoolyard bullying episodes bystanders play a role by either reinforcing the bully's actions or by not intervening at all. In 2007, Espelage, Green, \&Wasserman [18] stated bystanders or witnesses are present in $85 \%$ of the cases involving bullying. Furthermore, they concluded there is evidence the bystander's active or passive involvement can substantially influence the occurrence of bullying.

Kärnä, Voeten, Poskiparta, and Salmivalli [19] examined whether the bystanders' behaviors in bullying situations influenced vulnerable students' risk for victimization. Catanzaro [20] showed similar result with female teen victims. The results from multilevel models indicated the associations between victimization and its two risk factors social anxiety and peer rejection - were strongest in classrooms that were high in reinforcing bullying and low in defending the victims. This suggests that bystanders' behaviors in bullying situations moderate the effects of individual and interpersonal risk factors for victimization. Influencing these behaviors might be an effective way to protect vulnerable children from victimization. Bystanders have immense power to intervene and effectively stop bullying; yet, few children actually do so according to Siegel, [21] and Blank, et al [22].

There must be a change in the behavior of by-standers. Slaby (as cited in CQ Researcher, [23]) says bystanders are the most pivotal group of bullying influencers, since youth are so heavily influenced by their peers. If one stands by and watches bullying, then they are letting it happen in their community. However, if one stands up, the bullies do not experience success because there will be no acceptance of their behavior from peers.

Peer relationships are like oxygen that allows bullying breath and spread; peers can use these relationships as a cudgel, a weapon of shame against victims. However, even one good friend to a victim of bullying can help assuage the harmful consequences of harassment [24].

Bystanders who flee the scene of a bullying event unknowingly play a role in encouraging bullying, and allow bullies to enjoy disproportionate freedom at the expense of others, as well as breeding further conflict. Watching without intervening actually reinforces bullying behavior. Bystanders who speak out and do not remain silent in the face of inappropriate behaviors are committed to resisting such injustice, and discourage bullying. Despite wide recognition of the important role of student bystanders in influencing peer aggression in schools, little is currently known about what influences students to intervene in defense of peer aggression victims.

Coloroso [25](2005) found that though they play the least active role, bystanders are a critical element in bullying. With peers looking on and providing at least tacit support, the bully is no longer acting alone. The bystanders have become allies to the point of magnifying the supposed negative attributes of the target. If the bullying cycle is to be broken, the role of the bystander must be changed by starting with the four reasons bystanders give for not taking a stand against bullying: fear of getting hurt, fear of becoming a new target for the bully, fear of making the situation worse, and simply not knowing what to do. Talked about openly, these four reasons for remaining on the sidelines can be starting points for convincing bystanders to accept responsibility for recognizing bullying, refusing to be part of it, responding effectively, and reporting it to proper authorities.

Addressing the impact of peer bystanders on school bullying, a cross-sectional study by Trach, Hymel, Waterhouse, and Neal [26] examined whether student responses to bullying they witnessed varied as a function of sex and grade. Results indicated significant differences across sex and grade level, such that younger students and girls were more likely to report taking positive action than were older students and boys by directly intervening, helping the victim, or talking to an adult. Generally, boys and girls were equally likely to report they "ignored or avoided the person(s) who bullied" although reports they "did nothing" increased with grade level.

Dixon, Smith, and Jenks [27](2004) demonstrating that bullying and its management is embedded within the network of relationships which together form the school system, a range of issues and dilemmas relevant to all schools are highlighted and discussed. By joining in bullying or forming an audience, other children's reactions contribute to the expected social outcomes and consequently reinforce bullying behavior according to Andreou, Vlachou, \& Didaskalou [28].

Kärnä, Voeten, Poskiparta, \& Salmivalli [19] examined whether the bystanders' behaviors in bullying situations influence vulnerable students' risk for victimization. The results from multilevel models indicated the associations between victimization and its two risk factors-social anxiety and peer rejection-were strongest in classrooms that were high in reinforcing bullying and low in defending the victims. 
This finding suggests that bystanders' behaviors in bullying situations moderate the effects of individual and interpersonal risk factors for victimization. Influencing these behaviors might be an effective way to protect vulnerable victims from victimization. According to Davis and Nixon [29] peer mistreatment can harm young people's sense of belonging, safety, and connection to school. Students who feel unsafe or alienated are less likely to learn.

Bystanders are potentially in a position to challenge bullying as soon as it occurs according to Cowie [10]. In a study completed by Frey, Hirschstein, Snell, van Schoiack, Mackenzie, and Broderick [30] the findings indicated those in the intervention group reported enhanced bystander responsibility, greater perceived adult responsiveness, and less acceptance of bullying/aggression than those in the control group. Self-reported aggression did not differ between the groups. Implications for future research on the development and prevention of bullying are discussed by the authors of this study.

Research has shown peer bystanders are present during most bullying episodes and may contribute to the derogation of victims and the cycle of violence. Correia, Alves, Tomas de Almeida, and Garcia [31] examined how peer onlookers treat victims of bullying based on their status within the population. These researchers found when participants cast the physical bullying victim in a positive light, (i.e. "ingroup") less victimization occurred after the bullying incident. Therefore, if the victim was cast in a negative light, (i.e. "outgroup") more victimization occurred after the incident. Secondarily, these researchers also found when asked to convey a certain image to their peers, students would respond to victims in different ways. For example, if students were asked to convey a positive image they would victimize the "outgroup" member more than the "ingroup" member. An article by Andreou, Vlachou, Didaskalou [28] in School Psychology and cited by several sources found peers are of great importance in developing, maintaining or altering the social environment in which victimization problems occur.

Bystanders have immense power to intervene and effectively stop bullying; yet, few children actually do so. It is indisputable that peer interactions play a vital role in school bully-victim problems (Salmivalli, 2001 as cited in Andreou, Vlachou, \& Didaskalou [28]). By joining in bullying or forming an audience, other children's reactions contribute to the expected social outcomes and consequently reinforce bullying behavior. A final consideration made by Hodges, et al (1999, as cited in Low, Frey, and Brockman [32]) is that the actions of supportive friends may have different influences on overt aggression than they might have on gossip. Whereas the friendship of an aggressive or popular peer "might discourage overt aggression."

\section{Why Bystanders Behave as They do}

Bullying takes place in social settings with many onlookers aware of the distress caused to victims. Bystanders can play a crucial role in determining whether action is taken to challenge bullying or whether it goes unchecked. Peer and school level factors work in concert in shaping behavior [32]. Unfortunately, we know little about the reactions of peers who witness bullying, known as bystanders.

In his work Sutherland [33], noted there is a combination of school- and peer-level factors contributing to bullying, victimization, and sexual harassment. Howard [34] agreed that peer bystanders are present during most bullying episodes and may contribute to the derogation of victims and the cycle of violence. Howard's study examined the differential effects of peer bystander behavior on participant's perceptions and treatment of a victim of bullying. Several individual differences including pro-social attributes, tolerance for aggressive solutions to social conflict, and school climate and were examined as moderators of the effect of bystander behavior on victim outcomes. Bystander behavior varied to include four conditions 1. Active, 2. Passive, 3. Complicit, and 4.Control-No Bullying. This suggests that predicting peer responses to bullying involves a complex set of unique and combined individual and social factors.

How bystanders behave depends on their bystander status: (a) outsiders, who did not experience bullying among their peers; (b) defenders, who were likely to help the victims in bullying episodes; (c) guilty bystanders, who did nothing to help bullied peers but felt guilty about it; and (d) unconcerned bystanders, who witnessed peers being bullied, without feeling responsible. Bystanders' behaviors in bullying situations moderate the effects of individual and interpersonal risk factors for victimization. Influencing these behaviors might be an effective way to protect vulnerable children from victimization.

Most bystanders would like to intervene; at least $80 \%$ of peers find bullying and name-calling unpleasant to witness but admire those who intervene. However, a gap exists between their attitudes toward name-calling and their behavior. Most watch and do not intervene to stop it. Aboud and Joong [35] examined social psychological explanations for bystander apathy in light of developmental evidence. The authors' research paradigm now uses various socialization mechanisms such as modeling, role playing, and induction to overcome the inhibitions to act. The results the authors present here identify the specific assertive interventions that are most acceptable to bystanders and most effective with the antagonists.

Certain factors determine where an individual will be within the bullying climate. Mouttapa, Valente, Gallaher, Rohrback, and Unger [6] found the friendship network and the pattern of friendships among individuals within a group are important aspects of adolescent school bullying.

Pellegrini, Long, and Jeffery [36] stated many of the findings in their research were troubling, especially the finding that attitudes towards bullying become more positive with time. As peer groups, schools, and families are major socialization agents of young adolescents, they should be made aware of these views. The negative consequences of 
these views for both victims and others should be presented to youngsters.

Although children's reticence to intervene as bystanders to bullying is well established, the reasons for their inaction remain unclear. One possibility is they are incapable of generating appropriate response strategies in these situations. A study conducted by Rock and Baird [37] examined the number and type of strategies children ( $\mathrm{N}=104,6-11$ years) could generate for bystanders to a variety of bullying situations. Across bullying situations, older children generated more strategies than did younger children. Children most often suggested the bystander confront the bully directly followed by the suggestion the bystander find a teacher for help or comfort the victim. An exclusion incident prompted more frequent proposals that the bystander help by comforting the victim while a pushing incident prompted more frequent appeals to a teacher. A priming story related about a peer bystander intervening successfully in a bullying incident boosted strategy production in girls but did not duplicate the same results in boys.

A study by Stevens, Bourdeaudhuij, and Oost[38] revealed anxiety among peers that they might lose social influence and be bullied themselves, The inability to handle bully-victim problems in an effective way and address the special attention that should be placed to students' perceived efficacy in dealing effectively with bully-victim problems in order to develop a more protective social environment were also revealed (As cited in Andreou, Vlachou, \& Didaskalou, [28])

Despite wide recognition of the important role of student bystanders in influencing peer aggression in schools, little is currently known about what influences students to intervene in defense of peer aggression victims. A longitudinal study conducted by Barchia and Bussey [39] involving 1,167 primarily white adolescents (aged 12-15 years, 613 females) investigated the role of social cognitive factors and empathy as predictors of students defending victims of peer aggression. High levels of collective efficacy beliefs in the ability of students and teachers to work together to stop peer aggression were associated with higher frequency of defending behavior over time. For girls, over a period of time, empathy was also associated with defending the victim.

Aboud and ]oong [35] conducted research aimed at understanding how elementary school children, as potential bystanders, reacted to name-calling episodes. Although the authors' interest is in name-calling, the literature on bullying is relevant since name-calling is the most common form of bullying with other less common forms of bullying being physical harm, exclusion, and rumors. The authors first outlined some developmental evidence about bullies and victims in order to set the stage for their focus on bystanders. Because name-calling episodes generally occur in unsupervised school settings and victims are usually too emotionally distressed to retaliate, it is left up to peer bystanders to intervene.

Yibling, Doyle, Kalvin, Jianjun, and Lerner [40] found peer support positively predicted behavioral and emotional school engagement, whereas associating with problem-behaving friends and bullying involvement were negatively associated with both aspects of school engagement. When students were older, the positive influences of positive peer support on emotional engagement appeared stronger. It was also stated by Flaspohler, Elfstrom, Vanderzee, Sink, and Birchmeier [41] that a strong peer acceptance and support group is essential to be productive in school and society. Validation from friends provides psychosocial support that leads to healthy development and adjustment according to Ladd, 1990; Ladd, Kochenderfer, \& Coleman, 1996; as cited in Low, Frey \& Brockman, [42].

A survey conducted by Davis and Nixon [29] indicated when young people feel included by their peers, they are less likely to be hurt by bullying. This finding suggests that bystanders do not have to "stand up" to bullies to help; instead, small, quiet actions of support, such as calling the bullied student at home to encourage him or her, can also be effective. Thus, it is society's responsibility to teach young people when they become aware of peer mistreatment there are many ways to initiate positive action to end that mistreatment.

A study conducted by Flaspohler, Elfstrom, Vanderzee, Sink, and Birchmeier [41] underscores the value of efforts to promote social support from peers and teachers in both universal bullying prevention programs and school climate initiatives. Furthermore, results support further investigation into the possible contributions of bystanders in supporting school-wide bullying prevention/school climate strategies.

Siegel's [21] research aim was to contribute to the literature by examining the relationship between situational empathy and peer intervention when witnessing bullying. Other theoretically important factors regarding the type of bullying and the gender of the bully and the victim were also examined. Accordingly, the three research questions answered in this study were the following: (1) Does witnessing bullying elicit empathy towards victims of bullying? (2) What peer intervention strategies do middle-school students report when they witness bullying? (3) Does empathy and gender predict reported peer intervention? Consistent with hypotheses, results suggested that (1) children were more likely to intervene in physical bullying than relational bullying; (2) children reported instrumental intervention strategies most frequently in both bullying situations; and (3) both empathy and gender significantly contribute to children's intervention behavior similarly for both bullying situations. Gender findings were that girls were more likely to help overall. While boys and girls responded similarly to physical bullying, they responded very differently to relational bullying.

Dunn [43] explored the role of the bystander from the perspective of the question "What meaning do students give to their experiences of acting in response to witnessing bullying?" Despite physical and emotional risk, a small number of students do take action to stop bullying - these students have been called 'upstanders' or 'defenders' and their intervention in bullying signals that bullying is not 
acceptable. Despite their important role, there is little research exploring the pro-social actions of student upstanders.

\section{Resources to Help Bystanders, Parents, and Schools to Combat Bullying}

To help prevent bullying, we need to determine what factors are related to peer intervention in bullying. Numerous studies have suggested that empathy is related to pro-social behavior in children in a variety of situations; yet, bullying situations remain relatively unexplored in the literature. A discussion about actions bystanders can take ranging from measures that involve the least amount of personal risk to those that require the greatest courage must be accomplished. Hazler and Carney [44] provides critical characteristics of effective bullying prevention programs. Ahed and Eliza (as cited in Pellegrini, et al, [25] explored different components of shame management skills that might be related to getting involved in bystander intervention. Their research found bystanders who were willing to intervene to prevent further bullying were less inclined to blame the victim, take revenge on the victim, or hit out at something if they were caught hurting someone else. The bullies thought they were merely joking when actually their behavior was considered bullying from the bystanders' and the victims' points of view. This study finally discussed characteristics and categories of school bullying and the implications for interventions. Pellegrini [3] underscores the value of efforts of peers and teachers in both universal bullying prevention programs and school climate initiatives.

There is a plethora of literature on school climate. According to most of the literature, the largest group that constitutes the school environment relating to bullying behavior is the peer bystanders. If you are going to change the school climate of bullying, the primary target should be bystanders. The point of involving the school in prevention programs to engage bystanders and not only adult authorities are more important, other students. Siegel [21] stated that limiting bullying can be achieved if the school climate is not permissive. Changing bystander attitudes are the way to change the school climate. Student bystanders are essential in addition to adult authorities. Some bystanders may have seemed indifferent because they do not know what to do, and others may have been encouraging the aggressor by providing an audience. But most are opposed to bullying in principle, and by 11 or 12 years of age, they may be able to act accordingly if they are helped to acknowledge the inconsistency between their beliefs and their behavior according to Harvard Medical School Health (2001).

A study conducted by Flaspohler, Elfstrom, Vanderzee, Sink, and Birchmeier [41] underscored the value of efforts to promote social support from peers and teachers in both universal bullying prevention programs and school climate initiatives. Furthermore, results support further investigation into the possible contributions of bystanders in supporting school-wide bullying prevention/school climate strategies.

Lodge and Frydenberg [45] developed features of a universal coping program and common elements of successful antibullying interventions are highlighted. It is clear that peers play a central role in school bullying and teaching young people strategies to cope may be a positive step toward promoting peaceful schools.

Peer victimization has been a focus of both research and prevention program development. This problem is typically measured from the victim's and aggressor's perspectives. However, prevention programming often includes the additional perspective of the bystander. Generally, programs may be either curriculum based or peer led. They may focus on social skills or on restorative justice (i.e., forgiveness). Programs may focus specifically on the participants involved, or they may involve the entire school in systemic interventions.

It can be concluded the final verdict depends on some promising programs that take advantage of bystanders to combat bullying. Part of the bystander role change in any program is to raise awareness of the need to improve peer relationships by teaching empathy, adopting whole school awareness and implementing peer monitoring systems within the school framework.

Arnette and Walsleben (1998) (as cited in Andreou, E., Vlachou, A., \& Didaskalou [28]) established that buddy systems can also encourage reporting. Students can be paired with a friend or older student. These buddies would be someone on whom victims can depend for help when bullying occurs. In 2011, Coloroso [46] stated educators can use everyday words and actions to create a different climate in their schools. This new climate must include a deep caring and sharing that is devoted to breaking the current cycle of violence and exclusion. It is a daunting but necessary task.

Lusted [47] described peer mediation as a strategy where students themselves are taught to help resolve conflicts among their peers. It also presented the experiences of students at the South Meadow Middle School in Peterborough, New Hampshire where middle school students have been trained as peer mediators. He also reported the students who are involved in the conflict sign a contract at the end of the mediation about changing their behaviors. However, Lodge and Frydenberg [45] stated trained peer mediators were rarely identified, either by the teachers or students, as a preferred source of help. Murray's [48] findings suggested a perceived need for improved teacher awareness of students' perceptions pertaining to peer harassment issues.

Australian research examined peer perceptions and responses, together with factors associated with bystander behavior. The authors' research suggests that teaching peers to cope may assist in combating bullying in school by effecting change at the peer group level. Some of the most innovative, intensive, grassroots uses of peer relationships to reduce bullying, such as the You Have-the Power! in Montgomery County, Maryland, have not been scientifically evaluated. 
Howard [34] provided concrete situations for use in evaluating the responses of boys to their self-reports related to an actual event. Prior to coming to the lab, boys provided self-reports of pro-social behaviors, social perspective-taking, tendency to morally disengage, normative beliefs about bullying, personal history of bullying, and their respective school's climate. Each participant then played a game of Cyberball with three video characters. Frequency, sequence, and latency of ball-throwing to each cyber player were recorded. Participants also completed two surveys about their social preference and Belief in a Just World views of the victim. Results did not support main effect hypotheses regarding direct bystander behavior. However, boys' tendency to morally disengage and their normative beliefs about aggression moderated the effect of bystander behavior on boys' response to the victim.

The authors of this article recommend Davis and Davis [49] Empowering bystanders in bully prevention, Grades $K-8$ for presenting school staff with knowledge and skills for empowering student bystanders and changing school-wide attitudes toward bullying. This provides a wide range of realistic, safe, and effective options that bystanders can use during or after bullying situations. The approach is both research-based and practical. It provides specific techniques for teaching empathy and social problem solving skills, limiting the rewards of bullying behavior, and building a partnership between students and staff to create a positive and inclusive peer culture.

\subsection{Established Anti Bullying Programs with a Bystander Component}

The following are several bully prevention programs that have a vibrant bystander component. Programs aimed at reducing bullying must be established with a bystander component to the initiative. Wiens, Dempsey, and Allison [50] found that sixth graders receiving a bullying prevention program where the victim, aggressor, and bystander perspectives are incorporated. The perspective of the bystander should be included in future research and evaluation.

The development of systemic interventions began with Dan Olweus, who was the first to suggest the integration of common elements; his work culminated into what has now become the standard in antibullying programs. The goal of such programs is to teach students social skills that will allow them to create healthy relationships. These programs focus not only on the perpetrators and the victims, but also on the students who are bystanders [51].

Since bullying is not limited to the United States. Every country is dealing with bullying as seen in England, Germany, Finland. English and German schools are investigating the effects of a novel virtual learning strategy ('FearNot!') to tackle bullying. The approach is intended primarily for victims to increase their coping skills and to heighten empathy and defense of victims by bystanders. It was found 'FearNot!' helped bystanders to become defenders in the German sub-sample while it had no such effect in the UK sub-sample [52].

FearNot! is an immersive learning intervention called Fun with Empathic Agents to achieve Novel Outcomes in Teaching that can be used in school and during the summer. School children spend a lot of time in relatively unstructured community environments, with minimally trained staff. FearNot! is designed to enhance the problem solving skills of current or potential victims of bullying through the encouragement of students to generate and evaluate a wide range of responses to bullying. FearNot! demonstrates how virtual learning can reduce victimization especially among children who are already experiencing repeated bullying. The advantages of the program are safety, engagement, and a low-cost and time-efficient way of coaching children to cope with different situations.

Salmivalli and Poskiparta [53], Kärnä, et al [54]) and Salmivalli, Kärnä, \& Poskiparta, [55] described the Finnish program KiVa (established in 2006) which has a strong emphasis on influencing onlookers to support the victim rather than encouraging the bully. Finland is making bullying prevention a priority in Finnish schools: The $\mathrm{KiVa}$ antibullying program has been widely implemented in Finnish comprehensive schools since 2009. KiVa includes both universal and indicated actions to reduce bullying. The study completed by Salmivalli and Poskiparta [53] reports the effects of $\mathrm{KiVa}$ on nine different forms of being bullied in a sample of 5,651 fourth to sixth graders from 78 schools (39 intervention, 39 control). To date findings show a well-designed, research-based program can thwart multiple forms of being bullied, and there might be no need to develop specific programs for different forms of bullying.

Steps to Respect: A Bullying Prevention Program is a school-wide program that explicitly addresses relational aggression. Malicious gossip and social exclusion are two examples of relational aggression. The program deals with the development of universal intervention, retaliation beliefs, and supportive friends according to Low, Frey, and Brockman [32].

McGraw [56] details the Band Around Sevices program primarily used with eighth graders who sign a pledge that they will not bully or harass others nor will they support it. They commit to wear a bracelet which identifies them as someone who will assist their school in being a safe and supportive place [13].

Dunn's [43] findings were represented using five narrative exemplars and a description of the five themes identified from the thematic analysis. The first theme, Feeling Sensitive to Bullying, speaks to participant sensitivity in noticing bullying and in their strong personal responses to witnessing bullying. The theme, Deciding to Face the Risks, describes reactions to witnessing bullying and motivations for intervening. The theme, Knowing What to Do, illustrates participants' complex understanding of their social context and the multiple strategies and skills used. The theme, Thinking About the Bigger Picture, depicts how participants 
connected their actions to school strategies and larger issues. The final theme, Questioning "Does it Make a Difference?" speaks to participants' ambivalence about the impact of their actions to stop bullying. In exploring the meaning of these findings, Dunn offered comparisons to classical theory on bystander action and a parallel motivational model. The experiences of participants provided implications for schools in creating bullying prevention and intervention programs so that schools are not put in the role of the bystander. Implications for future research were offered, particularly regarding the impact of upstanders on other students.

\subsection{An Effective Bully Prevention}

The many programs cited in this paper have a number of points in common. The following is an alphabetical list of the myriad points in developing an effective anti-bullying program:

- Caring faculty

- Change in school climate

- Change society's acceptance of bullying

- Class room management support

- Clear policies and procedures

- Comprehensive

- Consistent

- Diversity training

- Educate legislators and professional organizations

- Explanation of the depth and breadth of bullying to all stakeholders

- Input from all stakeholders

- Integrated systemic structured approach

- Intervention program

- Managed effectively by all stakeholders

- Monitor for agendas/politics/media

- Monitoring of bullying locations

- Needs analysis

- Parent and community involvement

- Proactive

- Raise student awareness

- Reporting system

- Review federal/state laws

- School safety program includes bullying prevention

- School system wide implementation

- Social skills training

- Strong leadership

- Team approach

- Training and knowledge of bullying to all stake holders

- Two way communication with all stake holders

- Understand family patterns/characteristics

- Use all community resources

- Whole school system involvement

\section{Closing}

Bullying is a considerably common form of peer violence and harassment occurring within schools and communities.
Although most incidents of bullying are witnessed by peers, the majority will not take action to stop bullying which provides tacit evidence that bullying is permissible. It is our duty as educators to change the role of the bystander to be defined as the major component of any anti-bullying program.

As bystanders you can stop bullying and you need to know the warning signs if you're concerned that a child might be or become a victim of excessive teasing or bullying:

- Withdrawal

- Frequent crying

- Complaints of stomach-aches or headaches with no apparent cause

- Sudden drop in grades

- Not wanting to go to school

- Give a child space to talk. Be empathetic

- Help the child problem solve as to ways to respond; such as walking away, using humor, making new friends, seeking out a teacher or guidance counselor, etc.

You see, bullying is about intimidation and control; it gives bullies a sense of power. Bullies want that power over others because deep inside they feel powerless and inadequate. Bullying is also a result of boredom or having no sense of direction.

The authors found there can be no bullying without bullies. However, they cannot be successful in their cruel deeds without the complicity of bystanders. These not-so-innocent bystanders are the supporting cast who aid and abet the bully through acts of omission and commission. Another potential actor can bring the curtain down on this tragedy. This character--the antithesis of the bully--gives hope that one can break out of the trap of comradeship. This character can appear in three different and vital roles: resister, defender, and witness. Bullying can be challenged even more dramatically when the majority stands up against the cruel acts of the minority.

\section{REFERENCES}

[1] Harvard Medical School Health. (2001). Bullies and their victims. Health Letter Harvard Mental Health Letter, 18(5), 4-6.

[2] Padgett, S., \& Notar, C. E. (2013). Antibullying programs for middle/high schools. National Social Science Journal, 40910, 88-93.

[3] Pellegrini, A. D. (2002). Bullying, victimization, and sexual harassment during the transition to middle school. Educational Psychologist, 37(3), 151-163.

[4] Brown, B., Dolcini, M. \& Leventhal, A. (1997). In: Health risks and developmental transitions during adolescence. Schulenberg, John (Ed.); Maggs, Jennifer L. (Ed.); Hurrelmann, Klaus (Ed.); New York, NY, US: Cambridge University Press, 1997. pp. 161-189. [Chapter].

[5] Pellegrini, A. D., Long, D., Solberg, D., Roseth, C., DuPuis, 
D., Bohn, C., \& Hickey, M. (2010). Bullying and social status during school transitions. In S. R. Jimerson, S. M. Swearer, \& D. L. Espelage (Eds.), Handbook of Bullying in Schools: An International Perspective (pp. 199-2 10). New York: Routledge.

[6] Mouttapa, M., Valente, T., Gallaher, P., Rohrbach, 1. A., \& Unger, J. B. (2004). Victimization. Adolescence, 39(154), 315-355.

[7] Boulton, M. J. Smith, P. K., \& Cowie, H. (2010). Short-term longitudinal relationships between children's peer victimization/bullying experiences and self-perception. School Psychology International, 31(3), 296-311.

[8] Cowie, H. (2010). Peer support as an intervention to counteract school bullying: Listen to the children. Children \& Society, 25(4), 287-92.

[9] Cowie, H. (1998). Perspectives of teachers and pupils on the experience of peer support against bullying. Educational Research and Evaluation, 4(2), 108-125.

[10] Cowie, H. (2009). Peer support challenges school bullying, In Promoting emotional education: engaging children and young people with social, emotional and behavioural difficulties. Cefai, C., Cooper, (ed). pp. 85-92. London, England: Jessica Kingsley Publishers.

[11] Cowie, H., \& Hutson, N. (2005). Peer support: a strategy to help bystanders challenge school bullying. Pastoral Care on Education, 23(2), 40-44.

[12] Cheng, Y-Y., Chen, L-M., Ho, H-C., \& Cheng, C-L. (2011). Definitions of School Bullying in Taiwan: A Comparison of Multiple Perspectives. School Psychology International, $32(3), 227-243$.

[13] Notar, C. E., \& Padgett, S. (2013). From victim to bully. National Social Science Journal, 40(1), 79-83.

[14] Heinrichs, R. R. (2003). A whole-school approach to bullying: Special considerations for children with exceptionalities. Intervention in School and Clinic, 38(4), 195-204.

[15] Obermann, M-L. (2011). Moral disengagement among bystanders to school bullying. Journal of School Violence, 10(3), 239-257.

[16] Jeffrey, R. (2004). Bullying Bystanders. Prevention Researcher, 1(3), 7-8.

[17] Thornberg, R., \& Knutsen, S. (2011). Teenagers' explanations of bullying. Child \& Youth Care Forum, 40(3), 177-192.

[18] Espelage, D., Green H. D., \&Wasserman, S. (2007). Statistical analysis of friendship patterns and bullying behaviors among youth. New Directions for Child \& Adolescent Development, 118, 61-75.

[19] Karna, A., Voeten, M., Poskiparta, E., \& Salmivalli, C. (2010). Vulnerable children in varying classroom contexts: Bystanders' behavior moderate the effects of risk factors on victimization. Merrill-Palmer Quarterly, 56(3), 261-282.

[20] Catanzaro, M. F. (2011). Indirect aggression, bullying and female teen victimization: A literature review. Pastoral Care in Education, 29(2), 83-101.

[21] Siegel, N. M. (2009). Kids helping kids: The influence of situational factors on peer intervention in middle school bullying. Dissertation Abstracts International Section A: Humanities and Social Sciences, 69(7-A), pp. 2608.

[22] Blank, L.,Baxter, S.,Goyder, E.,Naylor, P. B.,Guillaume, L., Wilkinson, A., Hummel, S., \& Chilcott, J. (2010). Promoting well-being by changing behaviour: A systematic review and narrative synthesis of the effectiveness of whole secondary school behavioural interventions. Mental Health Review Journal, 15(2), 43-53.

[23] CQ Researcher. (2005). Bullying: Are schools doing enough to stop the problem. The CQ Researcher, 15(4), 103-123.

[24] Coloroso, B. (2005). A bully's bystanders are never innocent. Education Digest: Essential Readings Condensed for Quick Review, 70(8), 49-51.

[25] Rodkin, P. C. (2011). Bullying and the power of peers. Educational Leadership, 69(1), 11-16.

[26] Trach, J., Hymel, S., Waterhouse, T., \& Neale, K. (2010). Bystanders responses to school bullying: A cross-sectional investigation of grade and sex differences. Canadian Journal of School Psychology, 25(1), 114-130.

[27] Dixon, R., Smith, P., \& Jenks, C. (2004). Managing bullying and managing differences: A case study of one secondary school. Journal of School Violence, 3(4), 17-39.

[28] Andreou, E., Vlachou, A., \& Didaskalou, E. (2005). The roles of self-efficacy, peer interventions and attitudes in bully-victim incidents. School Psychology, 26(5), 545-562.

[29] Davis, S., \& Nixon, C. (2011). How can peers help? Educational Leadership, 69(1), 18-23.

[30] Frey, K. S., Hirschstein, M. K., Edstrom, L. V., \& Snell, J. L. (2009). Observed reductions in school bullying, nonbullying aggression, and destructive bystander behavior: A longitudinal Evaluation. Journal of Education Psychology, 101(2), 466-481.

[31] Correia I., Alves H; De Almeida, A. T.; \& Garcia D. (2010). Norms regarding secondary victimization of bullying victims: Do they differ according to the victim's categorization.. Scandinavian Journal of Psychology, 51(2), 164-70.

[32] Low, S., Frey, K. S., \& Brockman, C. J. (2010). Gossip on the playground: Changes associated with universal intervention, retaliation beliefs, and supportive friends. School Psychology Review, 39(4), 536-551.

[33] Sutherland, A. E. (2011), The roles of school climate and peers in bullying. Abstracts International: Section B: The Sciences and Engineering, Dissertation 72(4-B), pp. 2484.

[34] Howard, A. M. (2010). Socio-cultural, situational, and individual differences among peer bystanders of bullying: Who will help the victim? Dissertation Abstracts International: Section B: The Sciences and Engineering, $1-B)$.

[35] Aboud, F. E., \& Joong, A. (2008). Intergroup name-calling and conditions for creatig assertive bystanders. In Intergroup attitudes and relations in childhood through adulthood, Kevy, S. R. \& Killen, M. pp. 249-260. N. Y.: N. Y. Oxford University Press,

[36] Pellegrini, A. D., Long, \& Jeffrey, D. (2004). Part of the solution and part of the problem: The Roles of Peers in bullying, dominance and victimization during the transition 
from primary school through secondary school. In: Bullying in American Schools: A social-ecological perspective on prevention and intervention. Espelage, Dorothy L. (Ed.); Swearer, Susan M. (Ed.); Mahwah, NJ, US: Lawrence Erlbaum Associates Publishers, 004. pp. 107-117. [Chapter]

[37] Rock, P. F., \& Baird, J. A. (2012). Tell the teacher or tell the bully off: Children's strategy production for bystanders to bullying. Social Development, 21(2), 414-424.

[38] Stevens, V., Bourdeaudhuij, Ilse de, \& Oost, Paulette van (2000). Bullying in Flemish schools: an evaluation of anti-bullying intervention in primary and secondary schools. British Journal of Educational Psychology, 70(2), 195-210.

[39] Barchia, K., \& Bussey, K, (2011). Predictors of student defenders of peer aggression victims: Empathy and social cognitive factors. International Journal of Behavioral Development, 35(4), 289-297.

[40] Yibing L., Doyle L. A., Kalvin, C., Jianjun L., \& Lerner, R. M. (2011). Peer relationships as a context for the development of school engagement during early adolescence. International Journal of Behavioral Development, 35(4), 43-62.

[41] Flaspohler, P. D., Elfstrom, J. L., Vanderzee, K. L., Sink, H. E., \& Birchmeier, Z. (2009) Stand by me: The effects of peer and teacher support in mitigating the impact of bullying on quality of life. Psychology in the Schools, 46(7), 636-649.

[42] Dunn, S. T. M. (2010). Upstanders: Student experiences of intervening to stop bullying. Dissertation abstracts international section A: Humanities and Social Sciences, 71(1-A), 81

[43] Hazler, R. J., \& Carney, J. V. (2006). Critical characteristics of effective bullying prevention programs. Handbook of school violence and school safety: From research to practice. Jimerson, S. R. \& Furlong, M. (ed). pp. 275-291. Mahwah, NJ: Lawerence Erlbaum associates Publishers, xxiv.

[44] Lodge, J., \& Frydenberg, E. (2005). Toward promoting peaceful schools. Theory Into Practice, 44(4), 329-336.

[45] Coloroso, B. (2011). Bully, bullied, bystander ... and beyond: Help Students choose a new role. Education Digest: Essential Readings Condensed for Quick Review, 77(4), 36-39.
[46] Lusted, M. A. (2010). Peers Helping Peers. Faces (07491387), 27(3), 30-32.

[47] Murray, B. J. (2004). Peer harassment at school: A comparison of teachers' and students' perceptions of help seeking behavior in relation to type and severity of harassment. Dissertation Abstracts International Section A: Humanities and Social Sciences, 65(1-A), 69.

[48] Davis, S., \& Davis, J. (2007). Empowering bystanders in bullying prevention, Grades $K-8$. Champaign, IL, US: Research Press.

[49] Wiens, B. A., \& Dempsey, A. (2009). Bustander involvement in peer victimization: The value of looking beyond aggressors and victims. Journal of School Violence, 8(3), 206-215.

[50] Housekamp, B. M., Graham-Howard, M., Ashby, B., \& Fok-Trela, A. (2011). Treatment of adolescent victims of violence. The psychology of teen violence and victimization, Vols 1 and 2: From bullying to cyberstalking to assault and sexual violation; Prevention strategies for families and schools. Paludi, M. A. (Ed.); pp. 19-40. Santa Barbara, CA, US: Praeger/ABC-CLIO, 2011. lviii, 557 pp.

[51] Vannini, N., Enz, S., Sapouna, M., Wolke, D., Watson, S., Woods, S., Dautenhahn, K., Hall, L., Paiva, A., Andre, E. \& Schneider, W. (2011). FearNot!: A computer-based anti-bullying-programme designed to foster peer intervention. European Journal of Psychology of Education, 26(1), 21-44.

[52] Salmivalli, C., \& Poskiparta, E. (2012). Making bullying prevention a priority in Finnish schools: The KiVa antibullying program. New Directions for Youth Development, 2012(133), 41-53.

[53] Kärnä, A., Voeten, M., Little, T. D., Poskiparta, E., Kaljonen, A., \& Salmivalli C; (2011). A Large-Scale Evaluation of the KiVa Antibullying Program: Grades 4-6. Child Development, 82(1), 311-30.

[54] Kärnä, A., Voeten, M., Poskiparta, E.,\& Salmivalli, C. (2010). Bystanders' behaviors moderate the effects of risk factors on victimization. Merrill-Palmer Quarterly, 56 (3), 261-282.

[55] McGraw, C. (04/16/2011). Eighth-grader wins award for sticking up for 'Sevies'. The Gazette (Colorado Springs, CO) 